\title{
Diagnostic Failure of Cognitive Impairment in Nursing Home Residents May Lead to Impaired Medical Care
}

Björn Westerlind, Carl Johan Östgren, P. Midlöv and Jan Marcusson

The self-archived postprint version of this journal article is available at Linköping University Institutional Repository (DiVA):

http://urn.kb.se/resolve?urn=urn:nbn:se:liu:diva-159107

N.B.: When citing this work, cite the original publication.

Westerlind, B., Östgren, C. J., Midlöv, P., Marcusson, J., (2019), Diagnostic Failure of Cognitive Impairment in Nursing Home Residents May Lead to Impaired Medical Care, Dementia and Geriatric Cognitive Disorders. https://doi.org/10.1159/000499671

Original publication available at:

https://doi.org/10.1159/000499671

Copyright: Karger Publishers

http://www.karger.com/ 


\section{Diagnostic Failure of Cognitive Impairment in Nursing Home Residents May Lead to Impaired Medical Care}

Björn Westerlind ${ }^{1 *}$, Carl Johan Östgren², Patrik Midlöv ${ }^{3}$ Jan Marcusson ${ }^{4}$

${ }^{1}$ Department of Geriatrics, Jönköping, Region Jönköping County, and Department of Clinical and Experimental Medicine, Linköping University, Linköping, Sweden.

${ }^{2}$ Department of Medical and Health Sciences, Linköping University, Linköping, Sweden.

${ }^{3}$ Department of Clinical Sciences in Malmö, Center for Primary Health Care Research, Lund University, Malmö, Sweden.

${ }^{4}$ Geriatric Medicine, Department of Clinical and Experimental Medicine, Linköping University, Linköping, Sweden.

Short Title: Impaired medical care for nursing home residents with undiagnosed dementia.

${ }^{*}$ Corresponding Author

Björn Westerlind

Department of Geriatrics

County Hospital Ryhov

Region Jönköping County

SE 55185 Jönköping

Sweden

Tel: +46 (0) 102423242

E-mail: bjorn.westerlind@rjl.se

Keywords: Cognitive impairment - Nursing homes - Morbidity - Dementia - Heart failure 


\section{Diagnostic Failure of Cognitive Decline in Nursing Home Residents May Lead to Impaired Medical Care}

Westerlind B, Östgren C J, Midlöv P, Marcusson J

\section{Abstract}

Background/Objectives: Dementia and cognitive impairment are common in nursing homes. Few studies have studied the impact of un-noted cognitive impairment on medical care. This study aimed to estimate the prevalence of diagnostic failure of cognitive impairment in a sample of Swedish nursing home residents and to analyse whether diagnostic failure was associated with impaired medical care. Method: A total of 428 nursing home residents were investigated during 2008 - 2011. Subjects without dementia diagnosis were grouped by result of Mini Mental State Examination (MMSE), where subjects with $<24$ points formed a possible dementia group and the remaining subjects a control group. A third group consisted of subjects with diagnosed dementia. These three groups were compared according to baseline data, laboratory findings, drug use and mortality. Results: Dementia was previously diagnosed in 181 subjects (42\%). Among subjects without a dementia diagnosis, $72 \%$ were cognitively impaired with possible dementia (MMSE < 24). These subjects were significantly older, did not get anti-dementia treatment and had higher levels of brain natriuretic peptide compared to the diagnosed dementia group, but the risks of malnutrition and pressure ulcers were similar to the dementia group. Conclusions: Un-noted cognitive impairment is common in nursing home residents and may conceal other potentially treatable conditions such as heart failure. The results highlight a need to pay increased attention to cognitive impairment among nursing home residents. 


\section{Introduction}

Cognitive decline is highly prevalent in old age and constitutes a major predictor for longterm care use (1). The estimated frequency of dementia or cognitive impairment in longterm care populations varies between studies in different countries. A systematic review reports a median prevalence of $58 \%$, but with a considerable variation in prevalence $(12 \%$ $95 \%)$ as well as in sample sizes and diagnostic instruments (2). A report from the EU Commission estimates that approximately $80 \%$ of patients in long-term care suffer from cognitive decline or a diagnosed progressive memory disorder (1). A study performed at nursing homes in seven European countries and Israel reports a $70 \%$ prevalence of cognitive decline (3).

The Swedish National Board of Health and Welfare has estimated that $70 \%$ of residents in Swedish nursing homes may suffer from dementia (4). A recent study in a Swedish sample of nursing homes found cognitive impairment in $67 \%$ (5), but with cognitive assessment performed through a questionnaire sent to the nursing home staff and not a cognitive test. In a recent Norwegian study, cognitive investigation on admission to nursing homes found dementia in $84 \%$ (6). However, dementia is generally underdiagnosed, exemplified by nursing home studies in Scotland (7) and Austria (8) that found cognitive impairment in a total of $90 \%$ and $85 \%$ respectively, of which about one third was previously unknown. Moreover, a recent review reports a high proportion of undetected dementia not only in nursing homes, but in community-dwelling older people as well (9). Undiagnosed dementia means a lack of anti-dementia drug treatment, less awareness of possible inappropriate drugs, and inferior interaction and understanding between residents and caregivers, and has prognostic implications (10).

Few studies have studied the impact of un-noted cognitive impairment on medical care in other aspects. One study found that pain was more prevalent among cognitively impaired nursing home residents with dependency in activities of daily living (ADL) (5), but another study found that residents without dementia had more pain than patients with dementia (6). Previous community-based studies have shown a negative association between cognitive function and levels of N-terminal pro B-type natriuretic peptide (NT-proBNP), which is used as a marker of heart failure in clinical practice (11-13). Furthermore, dementia and cognitive impairment are related to an increased risk of malnutrition (14). B-type natriuretic peptide (BNP) is a hormone produced mainly by ventricular cardiomyocytes and with secretion associated to stretching of myocardial fibers. BNP is previously shown to be useful in confirming a heart failure diagnose, guide treatment and provide a prognosis. The sensitivity for heart failure due to systolic dysfunction is high (93-97\%), but as the specificity is somewhat lower $84 \%$ an echocardiography is recommended to confirm a heart failure diagnose $(15,16)$. There is no difference between the diagnostic accuracy of BNP and NT-proBNP (15).

Life expectancy in Sweden is among the highest in the European Union (17). Due to an increasing proportion of older people and a decreasing number of nursing home beds, the proportion of elderly people living in nursing homes is decreasing (18). A similar development in Norway has been shown to lead to a higher proportion of cognitively impaired elderly residents of nursing homes (19). Consequently, increased knowledge about cognitively impaired older people in nursing homes is essential. 
This study aimed to estimate the prevalence of diagnostic failure of cognitive impairment in a sample of Swedish nursing home residents and to investigate whether diagnostic failure of cognitive impairment was associated with impaired medical care.

\section{Materials and Methods}

\subsection{Study population}

The Study of Health and Drugs in the Elderly (SHADES) was a longitudinal cohort study that included older people living in 12 nursing homes in three different areas in the southern part of Sweden (Jönköping, Linköping and Eslöv) (20) during 2008-2011.

All residents living in the nursing homes on a permanent basis were invited to participate, whereas temporary residents were excluded as well as persons with language difficulties or under the age of 65 years. When a resident moved or died, the next person who moved in was invited to participate. A total of 428 study subjects were included.

\section{3:2 Methods of investigation}

Study subjects were examined at baseline by specially trained study nurses who also collected data from patient records on diagnoses and drug use. Diagnoses were collected with diagnosis codes according to the Swedish version of the International Classification of Diseases (ICD) - 10th version (21). Dementia was defined as any of the ICD codes F00 dementia in Alzheimer's disease, F01 vascular dementia, F02 dementia in other diseases classified elsewhere, F03 unspecified dementia, or G30 Alzheimer's disease.

Drugs prescribed for continuous use on the day of data collection were registered with codes according to the World Health Organization (WHO) Anatomical Therapeutic Chemical (ATC) classification system (22). The number of regularly used drugs, and the number of psychotropic drugs, defined as antipsychotics (ATC code N05A), anxiolytics (N05B), sedatives (N05C) and antidepressants (N06A) was calculated for each subject. Drugs taken as needed were not registered. Usage of cardiovascular and psychotropic drugs and substitution with cobalamin and folate in the groups were compared.

The in-person testing of study subjects was performed by the specially trained study nurses with assistance from the nursing home staff, and included measurements of weight, height, pulse and blood pressure. Blood pressure was measured three times at one-minute intervals in the right arm, while in a sitting position, and the mean value of the three measurements was used.

A standardized Swedish version of the Mini Mental State Examination (MMSE) (23), performed by the specially trained study nurses, was used to measure cognitive function. The scores range from 0 to 30 , with a score below 24 indicating cognitive dysfunction. MMSE could not be performed on all participants, due to reasons such as severe aphasia, refusal, blindness or impaired hearing.

Three groups of study subjects based on dementia diagnosis and cognitive function were compared. One group consisted of subjects with diagnosed dementia. Subjects without dementia diagnosis were grouped by result of MMSE, where subjects with MMSE $\geq 24$ formed a control group, and subjects with MMSE < 24 formed a group with undiagnosed cognitive impairment, subsequently named a "possible dementia group". Due to missing MMSE, 28 study subjects without dementia diagnosis were excluded. These subjects were not considered to differ from the study subjects in general according to answers from staff about their cognitive function.

The numbers of study subjects included, excluded or missing in this study, and the compared groups, are illustrated in Figure 1. 
Risk assessments based on interviews performed by the study nurses with the nursing home staff were performed. The modified Norton scale (MNS) (24) was used to assess the risk of developing pressure ulcers, and the short-form Mini-Nutritional Assessment (MNA-SF) (25) to assess the risk of malnutrition.

A questionnaire previously used by the Swedish National Study of Aging and Care (SNAC) (26) was performed, with 25 questions from the study nurses to the nursing home staff concerning ADL, need for care, different symptoms, and mood. The Cornell Scale for Depression in Dementia (CSDD), in this study based solely on information from staff members, was used to measure depressive symptoms (27).

Blood samples were drawn according to a standard procedure. Haemoglobin $(\mathrm{Hb})$ was analysed at local laboratories and remaining blood samples were stored at $-70^{\circ} \mathrm{C}$ in a freezer and analysed at the laboratory at the County Hospital Ryhov in Jönköping by high-pressure liquid chromatography. Several blood analyses were performed in order to compare the health status between the groups. To assess renal function, we used the formula for estimating glomerular filtration rate (GFR) according to updated Swedish guidelines (28). B-type natriuretic peptide (BNP), previously shown to have a close correlation with NT-proBNP (29), was analysed. For BNP measurements, a cut-off value of $100 \mathrm{ng} / \mathrm{L}$ has been previously suggested to indicate heart failure (30). For survival calculations, mortality dates were collected from the Swedish population register.

\section{3:3 Statistical analysis}

All statistical analyses were performed using SPSS Statistics version 24 (SPSS, Inc. Chicago, IL). Descriptive statistics were used for baseline characteristics. For comparison of baseline characteristics between the three groups, one-way ANOVA was used for continuous variables when the mean values were assumed to be normally distributed, Kruskal Wallis was used for continuous variables with considerable skewness, and the two-sided Pearson's chi-square test was used for discrete variables. A p-value of $<0.05$ was considered statistically significant.

To compare prevalence of drug classes and general symptoms in the three groups, two-sided Pearson's chi-square test was used. When the groups were small Fischer's test was used. To avoid mass significance in these analyses, $p$-values $<0.01$ were considered statistically significant and $p$ values $<0.05$ but $\geq 0.01$ were considered as non-significant tendencies. A Cox regression analysis with a survival plot of the three groups with adjustment for age and sex was created for survival calculations.

\section{Results}

This study included 400 study subjects (Figure 1) with a mean age of 85 years (range 65 to 101 years) of whom 234 (71\%) were women. 181 subjects had a dementia diagnosis. Among those assessed with MMSE without diagnosed dementia, 157 subjects had MMSE < 24 suggesting possible dementia and 62 subjects had MMSE $\geq 24$ and formed the control group. Baseline characteristics of the study population and the three compared groups are presented in Table 1. The groups differed significantly in age, weight, height and number of medications. The possible dementia group was significantly older than the diagnosed dementia group, but otherwise these two groups did not differ significantly in any other general characteristics (Table 1).

Blood analyses showed significantly higher BNP levels in the possible dementia group compared to the diagnosed dementia group. When we analysed the proportion of subjects with high BNP levels ( $\geq$ $100 \mathrm{ng} / \mathrm{L}$ ) there was a significantly higher proportion of high values in the group with possible 
dementia compared to the group with diagnosed dementia, which remained when subjects with known heart failure were excluded (Table 1).

The proportion of subjects on substitution with cobalamin and folate differed significantly between the three groups (Table 2). When subjects on substitution were excluded there were no significant differences in mean serum cobalamin or folate levels or prevalence of low values between the three groups (Table 1).

Polypharmacy was more common in the control group than in the other two groups. The possible dementia group were rarely treated with anti-dementia drugs (acetylcholinesterase inhibitors or memantine, Table 2). More subjects in the control group were treated with hypnosedatives than in the diagnosed dementia group (Table 2).

There were more subjects on therapy with diuretics and less substitution with cobalamin and folate in the possible dementia group compared to the diagnosed dementia group (Table 2).

The risks of malnutrition and pressure ulcers were assessed similarly in the diagnosed dementia group and the possible dementia group, and were significantly higher than in the control group.

Figure 2 shows survival curves for the three groups adjusted for age and sex. The differences in mortality between the groups were not significant.

\section{Discussion/Conclusion}

This study found differences of clinical importance between the cognitively impaired group with possible dementia (MMSE < 24) and the diagnosed dementia group.

Higher occurrence of elevated BNP levels in the possible dementia group may indicate under-treated heart failure, which is known to be associated with cognitive impairment (31) and dementia (32). Previous published data from SHADES showed a tendency towards higher cognitive function in subjects with established heart failure diagnosis compared to subjects without diagnosed heart failure (33). A reason for this, also suggested by a recent Norwegian nursing home study (34), may be that subjects with cognitive impairment generally have less attention paid to their physical symptoms which may cause undiagnosed physical disease. Furthermore, differences in cardiovascular drug treatment between the groups may reflect undiagnosed heart failure (Table 2). More diuretic use in the possible dementia group than in the dementia group may reflect symptomatic treatment of undiagnosed heart failure. The control group, without cognitive impairment and possibly with more somatic illness, uses the same amount of diuretics but also has a tendency to use more beta blockers.

BNP levels can be influenced by renal function and age (35). However, age differences in the present study, though significant, were not considered to influence BNP differences more than marginally, and there were no differences in renal function as measured by GFR (Table 1).

The age differences indicate that age might affect the amount of attention paid to cognitive impairment. Few subjects in the possible dementia group were on treatment with anti-dementia drugs, which presumably confirms that no dementia investigation was performed. Furthermore, substitution with cobalamin and folate were more common in the diagnosed dementia group (Table 2), possibly due to an established practice of starting substitution with these vitamins at levels below or in the lower normal area in connection with performing a dementia investigation. However, there were no differences in serum cobalamin or folate levels among individuals without substitution (Table 2). For subjects with diagnosed dementia, cognitive deficits may have constituted the main reason for moving into a nursing home, indicated by younger age and less cardiovascular medication in this group. For those without a dementia diagnose, more complex comorbidity may have contributed but been overlooked. More subjects in the control group were treated with 
hypnosedatives than in the dementia group, a difference that was due to more use of nonbenzodiazepine hypnotics in the control group.

Overall, the possible dementia group showed several similarities with the dementia group such as high risk of malnutrition and pressure ulcers (Table 2) and a similar mortality rate. However, neither survival curves (Figure 2) nor cumulative one year mortality (Table 2) differed significantly between the groups. Earlier studies have described that considerable proportions of nursing home residents have cognitive impairment but no dementia diagnosis (6-8). We found cognitive impairment in $72 \%$ of those without dementia assessed with MMSE. As MMSEs were missing for 28 subjects, we estimate that 177 subjects in the original sample of 428 may have undiagnosed dementia compared to 181 with a dementia diagnosis. This means that up to $84 \%$ were cognitively impaired which is on a level with previous studies with a similar approach $(6-8,34)$, but only half of them had a known dementia diagnosis. Furthermore, we believe that an MMSE cut off $<24$ is a conservative (and underestimating) MMSE value for cognitive impairment, considering that a recent study suggests MMSE cut off $\leq 26$ for older persons up to the age of 93(36).

Studies in the field are generally difficult to compare because there are differences in diagnostic tools and underlying populations, as previous reviews have pointed out $(2,9)$. MMSE is not a diagnostic tool but a screening instrument suggesting cognitive impairment, and a limitation in this study is the lack of proper diagnostic evaluation of the group with cognitive impairment named "possible dementia". There is a possible selection bias in SHADES as the participating nursing homes were chosen by convenience and nursing homes showing interest were selected. However, the inclusion of nursing homes from three different municipalities increases the chance that they were representative of Sweden. Another limitation is that the data were collected in the period 20082011, and the health status of older people living in nursing homes and traditions in drug use may have changed during the last few years. However, the total prevalence of cognitive decline in this study is in line with later collected data (6).

In conclusion, un-noted cognitive impairment in nursing home residents is common and may indicate other potentially treatable conditions such as heart failure. Undiagnosed cognitive impairment shows several similarities with diagnosed dementia such as a high risk of malnutrition and pressure ulcers and a similar mortality rate. In clinical practice these findings highlight the need to pay increased attention to signs of cognitive impairment in nursing home residents.

\section{Statements}

\subsection{Statements of Ethics}

The SHADES study protocol was approved by the Regional Ethical Review Board, Linköping (no.: M150-07 and 2016/67-32). Written informed consent was obtained from all study subjects. For subjects with cognitive impairment who were unable to understand the information, the next of kin were consulted.

\section{6:2 Disclosure Statement}

The authors have no conflicts of interest to declare.

\section{6:3 Funding Sources}

This study was financially supported by the Medical Research Council of Southeast Sweden (FORSS) and Futurum - Academy for Health and Care, Region Jönköping County.

\section{6:4 Author Contributions}


BW, CJÖ and PM contributed to the study concept and design. BW and JM contributed to the analysis and interpretation of data, and drafting the manuscript. All authors critically reviewed the work for important intellectual content and approved the final version of the manuscript. 


\section{References}

1. Social Protection Committee and the European Commission. Adequate social protection for long-term care needs in an ageing society Luxembourg: European Union; 2014 [cited 2018 Oct 24th]. Available from: Available from: http://ec.europa.eu/social/main.jsp?catld=738\&langld=en\&publd=7724.

2. Seitz D, Purandare N, Conn D. Prevalence of psychiatric disorders among older adults in long-term care homes: a systematic review. Int Psychogeriatr. 2010;22(7):1025-39.

3. Onder G, Carpenter I, Finne-Soveri H, Gindin J, Frijters D, Henrard JC, et al. Assessment of nursing home residents in Europe: the Services and Health for Elderly in Long TERm care (SHELTER) study. BMC Health Serv Res. 2012;12:5.

4. National Board of Health and Welfare. Demenssjukdomarnas samhällskostnader $\mathrm{i}$ Sverige 2012: Socialstyrelsen; 2014 [cited 2018 Oct 24th]. 2014-6-3:[Available from: https://www.socialstyrelsen.se/Lists/Artikelkatalog/Attachments/19444/2014-6-3.pdf.

5. Björk S, Juthberg C, Lindkvist M, Wimo A, Sandman P-O, Winblad B, et al. Exploring the prevalence and variance of cognitive impairment, pain, neuropsychiatric symptoms and $A D L$ dependency among persons living in nursing homes; a cross-sectional study. BMC Geriatr. 2016;16(1):154.

6. Roen I, Selbaek G, Kirkevold O, Engedal K, Testad I, Bergh S. Resourse Use and Disease Couse in dementia - Nursing Home (REDIC-NH), a longitudinal cohort study; design and patient characteristics at admission to Norwegian nursing homes. BMC Health Serv Res. 2017;17(1):365.

7. Lithgow S, Jackson GA, Browne D. Estimating the prevalence of dementia: cognitive screening in Glasgow nursing homes. Int J Geriatr Psychiatry. 2012;27(8):785-91.

8. Auer SR, Hofler M, Linsmayer E, Berankova A, PrieschI D, Ratajczak P, et al. Crosssectional study of prevalence of dementia, behavioural symptoms, mobility, pain and other health parameters in nursing homes in Austria and the Czech Republic: results from the DEMDATA project. BMC Geriatr. 2018;18(1):178.

9. Lang L, Clifford A, Wei L, Zhang D, Leung D, Augustine G, et al. Prevalence and determinants of undetected dementia in the community: a systematic literature review and a metaanalysis. BMJ Open. 2017;7(2):e011146.

10. Singer C, Luxenberg J. Diagnosing dementia in long-term care facilities. J Am Med Dir Assoc. 2003;4(6 Suppl):S134-40.

11. Daniels LB, Laughlin GA, Kritz-Silverstein D, Clopton P, Chen WC, Maisel AS, et al. Elevated natriuretic peptide levels and cognitive function in community-dwelling older adults. Am J Med. 2011;124(7):670 e1-8.

12. Feinkohl I, Sattar N, Welsh P, Reynolds RM, Deary IJ, Strachan MW, et al. Association of N-terminal pro-brain natriuretic peptide with cognitive function and depression in elderly people with type 2 diabetes. PloS one. 2012;7(9):e44569.

13. van Vliet P, Sabayan B, Wijsman LW, Poortvliet RKE, Mooijaart SP, de Ruijter W, et al. NT-proBNP, blood pressure, and cognitive decline in the oldest old: The Leiden 85-plus Study. Neurology. 2014;83(13):1192-9.

14. Bell CL, Lee AS, Tamura BK. Malnutrition in the nursing home. Curr Opin Clin Nutr Metab Care. 2015;18(1):17-23.

15. Mant J, Doust J, Roalfe A, Barton P, Cowie MR, Glasziou P, et al. Systematic review and individual patient data meta-analysis of diagnosis of heart failure, with modelling of implications of different diagnostic strategies in primary care. Health Technol Assess. 2009;13(32):1-207, iii. 16. de Freitas EV, Batlouni M, Gamarsky R. Heart failure in the elderly. J Geriatr Cardiol. 2012;9(2):101-7. 
Socialstyrelsen; 2018 [cited 2018 Oct 24th]. 2018-2-7:[Available from:

http://www.socialstyrelsen.se/Lists/Artikelkatalog/Attachments/20857/2018-2-7.pdf.

18. National Board of Health and Welfare. Statistik om särskilt boende: Socialstyrelsen;

2016 [cited 20193 January]. 2016-12-5:[Available from:

http://www.socialstyrelsen.se/Lists/Artikelkatalog/Attachments/20404/2016-12-5.pdf.

19. Helvik AS, Engedal K, Benth JS, Selbaek G. Prevalence and Severity of Dementia in

Nursing Home Residents. Dement Geriatr Cogn Disord. 2015;40(3-4):166-77.

20. Ernsth Bravell M, Westerlind B, Midlov P, Ostgren CJ, Borgquist L, Lannering C, et al.

How to assess frailty and the need for care? Report from the Study of Health and Drugs in the Elderly

(SHADES) in community dwellings in Sweden. Arch Gerontol Geriatr. 2011;53(1):40-5.

21. World Health Organization. International statistical classification of diseases and related health problems (ICD-10). 10th Ed ed. Geneva: WHO; 1992.

22. World Health Organization. ATC - Structure and principles: WHO Collaborating Centre for Drug Statistics Methodology; [updated 2011-03-25; cited 201823 August]. Available from: https://www.whocc.no/atc/structure and principles/.

$23 . \quad$ Folstein MF, Folstein SE, McHugh PR. "Mini-mental state". A practical method for grading the cognitive state of patients for the clinician. J Psychiatr Res. 1975;12(3):189-98.

24. Ek AC, Unosson M, Bjurulf $P$. The modified Norton scale and the nutritional state. Scandinavian journal of caring sciences. 1989;3(4):183-7.

25. Rubenstein LZ, Harker JO, Salva A, Guigoz Y, Vellas B. Screening for undernutrition in geriatric practice: developing the short-form mini-nutritional assessment (MNA-SF). J Gerontol A Biol Sci Med Sci. 2001;56(6):M366-72.

26. SNAC. SNAC-K Vårdsystem - Vårdsystem. The Swedish National Study on Aging and Care - Kungsholmen [cited 201917 February]. Available from:

https://snacsweden.files.wordpress.com/2013/11/undersc3b6kningsprotokoll.pdf.

$27 . \quad$ Alexopoulos GS, Abrams RC, Young RC, Shamoian CA. Cornell Scale for Depression in Dementia. Biol Psychiatry. 1988;23(3):271-84.

28. Swedish Agency for Health Technology Assessment and Assessment of Social Services. Methods to Estimate and Measure Renal Function (Glomerular Filtration Rate) - A Systematic Review 2013 [cited 2018 24th Oct]. Available from:

http://www.sbu.se/upload/Publikationer/Content0/1/Njurfunktion/Njurfunktion.pdf.

29. Mair J, Gerda F, Renate H, Ulmer H, Andrea G, Pachinger O. Head-to-head comparison of B-type natriuretic peptide (BNP) and NT-proBNP in daily clinical practice. Int J Cardiol. 2008;124(2):244-6.

30. Maisel AS, Krishnaswamy P, Nowak RM, McCord J, Hollander JE, Duc P, et al. Rapid measurement of B-type natriuretic peptide in the emergency diagnosis of heart failure. $\mathrm{N} \mathrm{Engl} \mathrm{J} \mathrm{Med.}$ 2002;347(3):161-7.

31. Vogels RL, Scheltens $P$, Schroeder-Tanka JM, Weinstein HC. Cognitive impairment in heart failure: a systematic review of the literature. Eur J Heart Fail. 2007;9(5):440-9.

32. Adelborg K, Horvath-Puho E, Ording A, Pedersen L, Toft Sorensen H, Henderson VW. Heart failure and risk of dementia: a Danish nationwide population-based cohort study. Eur J Heart Fail. 2017;19(2):253-60.

33. Bolmsjo BB, Molstad S, Ostgren CJ, Midlov P. Prevalence and treatment of heart failure in Swedish nursing homes. BMC geriatrics. 2013;13:118.

34. Jørgensen LB, Thorleifsson BM, Selbæk G, Šaltytè Benth J, Helvik A-S. Physical diagnoses in nursing home residents - is dementia or severity of dementia of importance? BMC Geriatr. 2018;18(1):254. 
35. Raymond I, Groenning BA, Hildebrandt PR, Nilsson JC, Baumann M, Trawinski J, et al. The influence of age, sex and other variables on the plasma level of $\mathrm{N}$-terminal pro brain natriuretic peptide in a large sample of the general population. Heart. 2003;89(7):745.

36. Kvitting AS, Fällman K, Wressle E, Marcusson J. Age-Normative MMSE Data for Older Persons Aged 85 to 93 in a Longitudinal Swedish Cohort. J Am Geriatr Soc. 2018;0(0).

\section{Figure and Table Legends}

Fig. 1. Flow chart and grouping of study subjects in the SHADES study.

Fig. 2. Cox regression, comparison of one year survival rates for the three groups.

Table 1. Baseline characteristics of the study population including comparison between groups based on dementia diagnosis and cognitive function.

Table 2. Prevalence of drug classes and some general symptoms including comparison between groups based on dementia diagnosis and cognitive function. 
Available for invitation

$$
n=664
$$

Excluded (palliative care, language problems, age $<65$ or died between consent signing and baseline examination) $n=49$ Denied participation $n=100$

Proxy opposed participation $n=87$

Included in SHADES

$$
n=428
$$

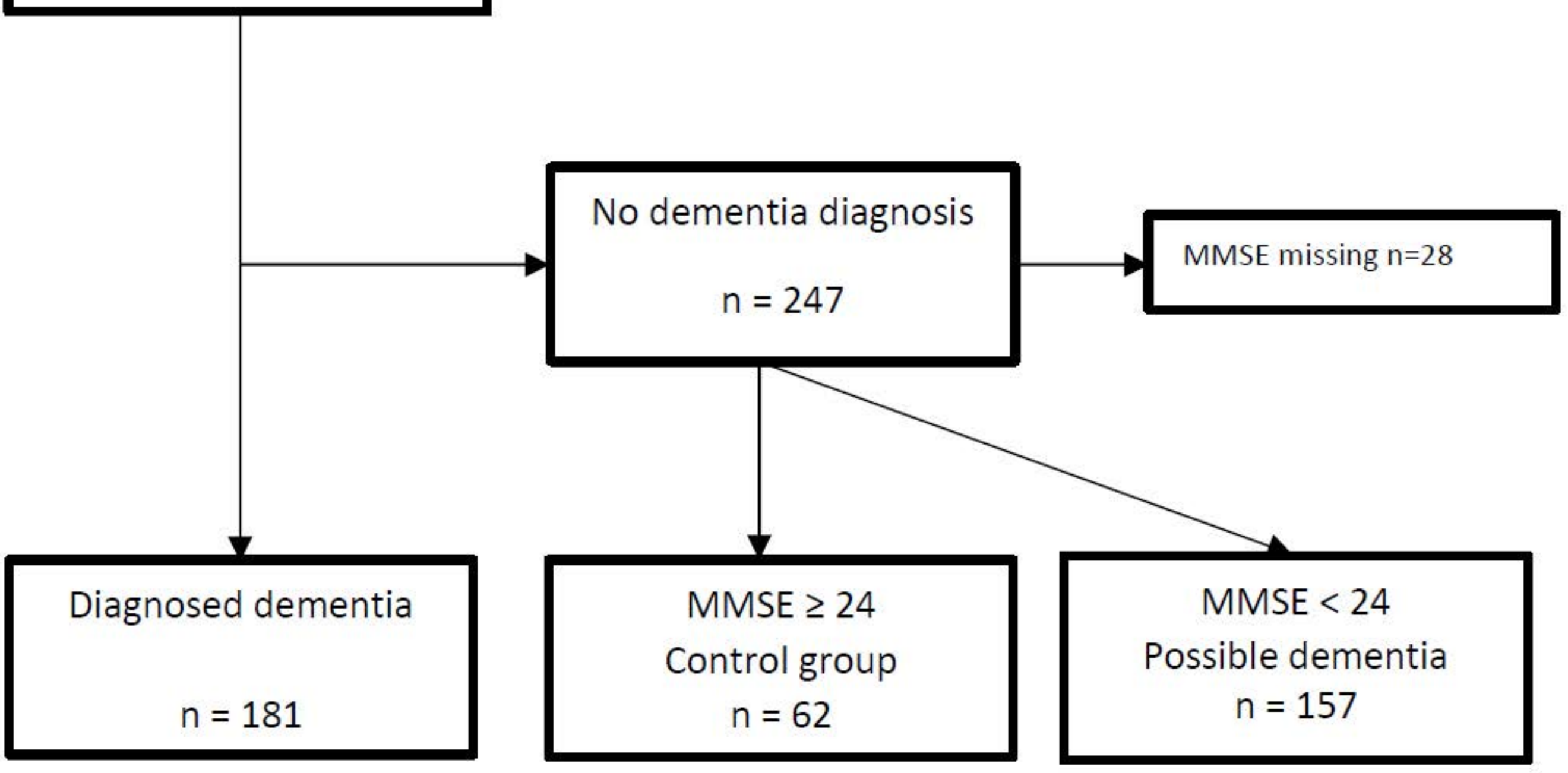


Survival curves for diagnosed dementia, possible dementia and control groups

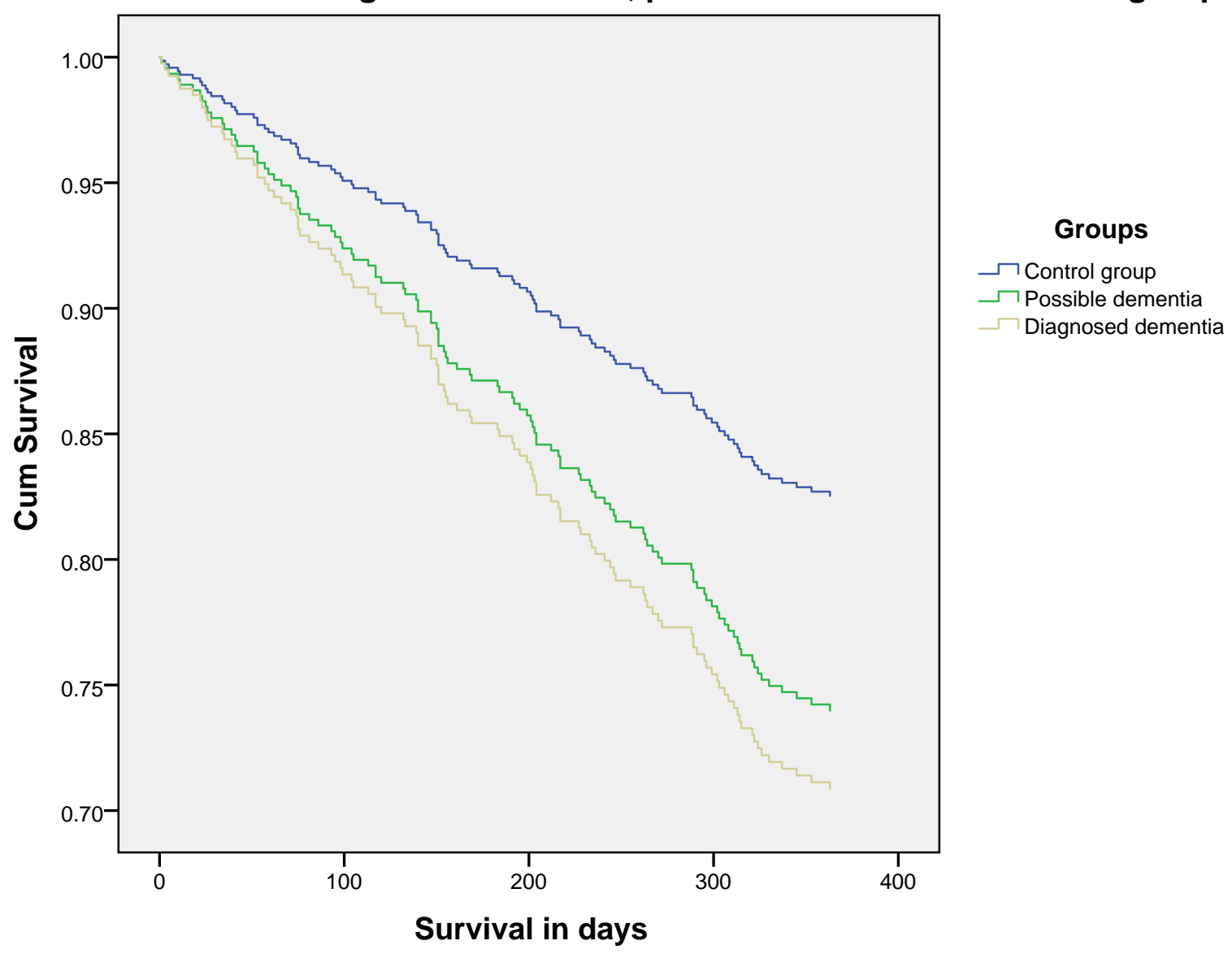


Table 1. Baseline characteristics of the study population including comparison between groups based on dementia diagnosis and cognitive function.

\begin{tabular}{|c|c|c|c|c|c|}
\hline & Total & $\begin{array}{l}\text { Diagnosed } \\
\text { dementia }\end{array}$ & $\begin{array}{l}\text { Control group } \\
\text { MMSE } \geq 24\end{array}$ & $\begin{array}{c}\text { Possible } \\
\text { dementia } \\
\text { MMSE }<24\end{array}$ & $p$-value \\
\hline \multicolumn{6}{|l|}{ General characteristics } \\
\hline Number & 400 & 181 & 62 & 157 & \\
\hline Age (years) mean $\pm S D$ & $85.0 \pm 6.9$ & $84.2 \pm 6.4$ & $84.9 \pm 7.0$ & $86.1 \pm 7.3$ & $0.031^{1, c}$ \\
\hline Women (\%) & 71.0 & 70.2 & 67.7 & 73.2 & $0.682^{2}$ \\
\hline Regular drugs (number) \pm SD & $6.9 \pm 3.1$ & $6.5 \pm 3.1$ & $8.0 \pm 3.3$ & $7.0 \pm 3.0$ & $0.005^{1, a}$ \\
\hline $\begin{array}{l}\text { Psychotropic drugs (number) } \pm \\
\text { SD }\end{array}$ & $1.2 \pm 1.2$ & $1.2 \pm 1,2$ & $1.2 \pm 1.1$ & $1.3 \pm 1.2$ & $0.988^{3}$ \\
\hline Weight $(\mathrm{kg}) \pm S D$ & $66.7 \pm 15.2$ & $66.0 \pm 15.2$ & $72.0 \pm 17.9$ & $65.4 \pm 13.6$ & $0.011^{1, a, b}$ \\
\hline Height $(\mathrm{cm}) \pm S D$ & $163.3 \pm 9.0$ & $162.9 \pm 9.0$ & $166.4 \pm 8.9$ & $162.6 \pm 8.8$ & $0.014^{1, a, b}$ \\
\hline $\mathrm{BMI}\left(\mathrm{kg} / \mathrm{m}^{2}\right) \pm \mathrm{SD}$ & $25.0 \pm 5.1$ & $24.8 \pm 5.2$ & $26.0 \pm 6.0$ & $24.7 \pm 4.5$ & $0.246^{1}$ \\
\hline Dementia diagnosis (\%) & 45.2 & 100 & 0 & 0 & $<0.001^{2, a, c}$ \\
\hline MMSE (points) $\pm S D$ & $\begin{array}{c}17.1 \pm 6.5 \\
\mathrm{n}=359\end{array}$ & $\begin{array}{c}13.6 \pm 5.5 \\
n=140\end{array}$ & $\begin{array}{c}26.3 \pm 1.9 \\
\mathrm{n}=62\end{array}$ & $\begin{array}{c}16.7 \pm 4.8 \\
\mathrm{n}=157\end{array}$ & $<0.001^{1, a, b, c, c}$ \\
\hline Pulse (beats/min) & $73 \pm 12$ & $74 \pm 13$ & $71 \pm 12$ & $72 \pm 12$ & $0.248^{1}$ \\
\hline Systolic blood pressure $(\mathrm{mm} \mathrm{Hg})$ & $134 \pm 23$ & $133 \pm 21$ & $136 \pm 21$ & $134 \pm 26$ & $0.625^{1}$ \\
\hline Diastolic blood pressure $(\mathrm{mmHg})$ & $72 \pm 12$ & $72 \pm 12$ & $70 \pm 11$ & $73 \pm 12$ & $0.183^{1}$ \\
\hline \multicolumn{6}{|l|}{ Blood analyses } \\
\hline $\mathrm{Hb}(\mathrm{g} / \mathrm{L}) \pm \mathrm{SD}, \mathrm{n}=371$ & $125.5 \pm 13.9$ & $125.4 \pm 14.1$ & $124.8 \pm 12.9$ & $126.0 \pm 14.3$ & $0.856^{1}$ \\
\hline P-glucose $(\mathrm{mmol} / \mathrm{L}) \pm S D(n=368)$ & $5.6 \pm 1.8$ & $5.7 \pm 1.9$ & $5.5 \pm 1.5$ & $5.5 \pm 1.7$ & $0.242^{3}$ \\
\hline Creatinine $(\mu \mathrm{mol} / \mathrm{L}) \pm S D(n=383)$ & $87.6 \pm 87.7$ & $86.1 \pm 33.7$ & $91.7 \pm 75.6$ & $87.7 \pm 32.9$ & $0.500^{3}$ \\
\hline Cystatin C (mg/L) $\pm S D(n=383)$ & $1.36 \pm 0.45$ & $1.30 \pm 0.39$ & $1.44 \pm \pm 0.62$ & $1.41 \pm 0.437$ & $0,067^{3}$ \\
\hline $\begin{array}{l}\text { eGFR }\left(\mathrm{ml} / \mathrm{min} / 1,73 \mathrm{~m}^{2}\right) \pm \mathrm{SD} \\
(\mathrm{n}=383)\end{array}$ & $54.1 \pm 15.8$ & $55.7 \pm 14.9$ & $54.7 \pm 18.0$ & 52.2 & $0.120^{2}$ \\
\hline Transthyretin $(\mathrm{g} / \mathrm{L}) \pm \mathrm{SD}(\mathrm{n}=382)$ & $0.215 \pm 0.057$ & $0.216 \pm 0.054$ & $0.226 \pm 0.050$ & $0.210 \pm 0.061$ & $0.204^{1}$ \\
\hline $\mathrm{TSH}(\mathrm{mIE} / \mathrm{L}) \pm \mathrm{SD}(\mathrm{n}=384)$ & $2.05 \pm 2.50$ & $2.16 \pm 2.24$ & $1.68 \pm 1.49$ & $2.08 \pm 3.05$ & $0.150^{3}$ \\
\hline Transferrin $(\mathrm{g} / \mathrm{L}) \pm \mathrm{SD}(\mathrm{n}=382)$ & $3.40 \pm 2.70$ & $3.49 \pm 3.53$ & $3.32 \pm 2.29$ & $3.34 \pm 1.50$ & $0.744^{3}$ \\
\hline Ferritin $(\mu \mathrm{g} / \mathrm{L}) \pm S D(n=385)$ & $149 \pm 189$ & $159 \pm 202$ & $124 \pm 219$ & $147 \pm 160$ & $0.155^{3}$ \\
\hline $\begin{array}{l}\text { Cobalamin, without substitution } \\
\pm S D(n=245)\end{array}$ & $338 \pm 236$ & $\begin{array}{c}353 \pm 250 \\
(n=96)\end{array}$ & $\begin{array}{c}299 \pm 138 \\
(n=39)\end{array}$ & $\begin{array}{c}339 \pm 251 \\
(n=110)\end{array}$ & $0.744^{3}$ \\
\hline $\begin{array}{l}\text { Cobalamin }<200 \mathrm{pmol} / \mathrm{L} \text { without } \\
\text { substitution }(\%)(\mathrm{n}=245)\end{array}$ & 18.4 & 14.6 & 17.9 & 21.8 & $0,408^{2}$ \\
\hline $\begin{array}{l}\text { Folate without subst } \pm \text { SD } \\
(n=294)\end{array}$ & $9.9 \pm 6.8$ & $\begin{array}{l}9.9 \pm 5.9 \\
(n=114)\end{array}$ & $\begin{array}{c}10.4 \pm 7.5 \\
(n=46)\end{array}$ & $\begin{array}{l}9.8 \pm 7.3 \\
(n=134)\end{array}$ & $0.239^{3}$ \\
\hline $\begin{array}{l}\text { Folate }<7 \mathrm{nmol} / \mathrm{L} \text { without } \\
\text { substitution }(\%)(\mathrm{n}=294)\end{array}$ & 32.7 & 26.3 & 37.0 & 36.6 & $0,182^{2}$ \\
\hline $\begin{array}{l}\text { 25-hydroxyvitamin D3 (nmol/L) } \pm \\
\text { SD }(\mathrm{n}=373)\end{array}$ & $45.8 \pm 22.1$ & $44.9 \pm 23.0$ & $50.3 \pm 21.2$ & $45.2 \pm 21.4$ & $0.046^{3, a}$ \\
\hline$B N P(n g / L) \pm S D(n=382)$ & $182 \pm 306$ & $155 \pm 226$ & $149 \pm 170$ & $226 \pm 406$ & $0.020^{3, c}$ \\
\hline$B N P \geq 100 \mathrm{ng} / \mathrm{L}(\%)(\mathrm{n}=382)$ & 50.8 & 43.3 & 51.7 & 58.9 & $0.019^{2, c}$ \\
\hline $\begin{array}{l}\text { BNP } \geq 100 \mathrm{ng} / \mathrm{L}(\%), \text { diagnosed } \\
\text { heart failure excluded ( } \mathrm{n}=288),\end{array}$ & 43,4 & 37,2 & 38,5 & 52,7 & $0.040^{2, c}$ \\
\hline
\end{tabular}

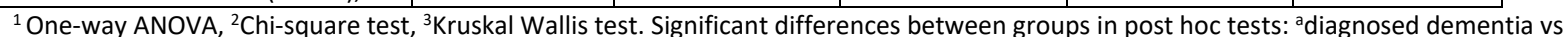
control group ${ }^{\mathrm{b}}$ possible dementia vs control group cdiagnosed dementia vs possible dementia.

Hb Haemoglobin MMSE Mini Mental State Examination, SD Standard Deviation, BMI Body Mass Index, Hb Haemoglobin, BNP B-type Natriuretic Peptide 
Table 2. Prevalence of drug classes and some general symptoms including comparison between groups based on dementia diagnosis and cognitive function.

\begin{tabular}{|c|c|c|c|c|}
\hline Parameter & Total & $\begin{array}{l}\text { Diagnosed } \\
\text { dementia }\end{array}$ & $\begin{array}{l}\text { Control group } \\
\text { MMSE } \geq 24\end{array}$ & $\begin{array}{l}\text { Possible dementia } \\
\text { MMSE }<24\end{array}$ \\
\hline Number of subjects & 400 & 181 & 62 & 157 \\
\hline Polypharmacy $\geq 10$ drugs $\%$ & 22.3 & $17.7^{* * a}$ & $38.7^{* * a b}$ & $22.3^{* * \mathrm{~b}}$ \\
\hline$\geq 3$ psychotropic drugs $\%$ & 15.3 & 15.5 & 16.6 & 15.3 \\
\hline $\begin{array}{l}\text { Psycholeptics \% } \\
\text { ATC: N05, Lithium and melatonin excluded }\end{array}$ & 48.9 & 43.1 & 53.2 & 52.2 \\
\hline $\begin{array}{l}\text { Antipsychotics \% } \\
\text { ATC: N05A, Lithium excluded }\end{array}$ & 13.3 & $18.2^{\# a}$ & $8.1^{\# a}$ & 9.6 \\
\hline $\begin{array}{l}\text { Hypnotics and sedatives \% } \\
\text { ATC: N05C, Melatonin excluded }\end{array}$ & 33.3 & $25.4 * *$ a \#c & $43.5^{* * a}$ & $38.3^{\# c}$ \\
\hline $\begin{array}{l}\text { Benzodiazepines, all \% } \\
\text { ATC: NO5BA, NO5CD }\end{array}$ & 18.3 & 16.6 & 14.5 & 21.7 \\
\hline $\begin{array}{l}\text { Nonbenzodiazepine hypnotics \% } \\
\text { ATC: NO5CF }\end{array}$ & 25.5 & 20.4 & 35.5 & 27.4 \\
\hline $\begin{array}{l}\text { Antidepressants, all \% } \\
\text { ATC: NO6A }\end{array}$ & 46.0 & 50.3 & 43.5 & 42.0 \\
\hline $\begin{array}{l}\text { SSRI \% } \\
\text { ATC: NO6AB }\end{array}$ & 33.3 & 34.8 & 22.6 & 35.7 \\
\hline $\begin{array}{l}\text { Anti-dementia drugs \% } \\
\text { ATC: NO6D }\end{array}$ & 15.8 & $32.0 * * a c$ & $1.6^{* * a}$ & $2.5^{* * c}$ \\
\hline $\begin{array}{l}\text { Antihypertensives, all \% } \\
\text { ATC: CO2, CO3, CO7, CO8, CO9 }\end{array}$ & 65.5 & $54.7^{* * a c}$ & $75.8^{* * a}$ & $73.9 * * \mathrm{c}$ \\
\hline $\begin{array}{l}\text { Diuretics \% } \\
\text { ATC: } \mathrm{CO} 3\end{array}$ & 48.0 & $37.6 * * a c$ & $62.9 * * a$ & $54.1^{* * c}$ \\
\hline $\begin{array}{l}\text { Loop diuretics \% } \\
\text { ATC: } \text { C03C }\end{array}$ & 38.8 & $32.0 * * a$ & $58.1 * * a \# b$ & $38.9^{\# \mathrm{~b}}$ \\
\hline $\begin{array}{l}\text { Spironolactone } \% \\
\text { ATC: CO3DA01 }\end{array}$ & 7.5 & $3.3^{\# a b}$ & $12.9^{\# a}$ & $10.2^{\# b}$ \\
\hline $\begin{array}{c}\text { Amiloride } \% \\
\text { ATC: } \text { CO3DBO1 }\end{array}$ & 1.3 & 0.6 & 1.6 & 1.9 \\
\hline $\begin{array}{l}\text { Thiazides, combinations included \% } \\
\text { C03A, C09BA, C09DA }\end{array}$ & 7.3 & $5.0^{\# c}$ & 3.2 & $11.5^{\# c}$ \\
\hline $\begin{array}{l}\text { Beta blockers \% } \\
\text { ATC: } \text { CO7 }\end{array}$ & 34.8 & $29.8^{* * a}$ & $50.0 * * a \# b$ & $34.4^{\# \mathrm{~b}}$ \\
\hline $\begin{array}{l}\text { ACE inhibitors or ARB, } \\
\text { ATC: } C 09\end{array}$ & 20.3 & 19.3 & 22.6 & 20.4 \\
\hline $\begin{array}{l}\text { Long acting nitrates } \% \\
\text { ATC: } \text { CO1DA }\end{array}$ & 8.8 & 6.6 & 9.7 & 10.8 \\
\hline $\begin{array}{l}\text { Cobalamin substitution \% } \\
A T C: B 03 B A, A 11 E A\end{array}$ & 36.3 & $44.2^{* * c}$ & 32.3 & $28.7^{* * c}$ \\
\hline $\begin{array}{l}\text { Folate substitution } \% \\
A T C: B 03 B B, A 11 E A\end{array}$ & 24.0 & $34.8^{\# a * c}$ & $21.0^{\# a}$ & $12.7^{* * \mathrm{c}}$ \\
\hline Urine incontinence (SNAC) \% & 70.8 & $76.7^{* * a}$ & $55.0 * * a \# b$ & $70.1^{\# \mathrm{~b}}$ \\
\hline Dizziness (SNAC) \% & 47.6 & $43.6^{\# c}$ & 41.7 & $54.5^{\# c}$ \\
\hline Insecurity (SNAC) \% & 69.0 & $79.3^{* * a c}$ & $53.3^{* * a}$ & $63.0 * * c$ \\
\hline Depressed mood (SNAC) \% & 61.1 & $69.3 * * a \# c$ & $48.3^{* * a}$ & $56.5^{\# c}$ \\
\hline CSDD $\geq 6$ points $\%$ & 13.7 & 16.1 & 13.1 & 11.3 \\
\hline Pain (SNAC) \% & 61.4 & 57.8 & 71.7 & 61.7 \\
\hline Malnutrition risk (MNA-SF $\leq 11 p) \%$ & 61.6 & $71.7^{* * a \text { \#c }}$ & $33.9 * * a b$ & $60.9 * * \mathrm{~b} \# \mathrm{c}$ \\
\hline Pressure ulcer risk (MNS $\leq 20 p$ ) $\%$ & 46.4 & $51.7 * * a$ & $22.6^{* * a b}$ & $49.7 * * b$ \\
\hline One year survival \% & 72.0 & 70.2 & 80.6 & 70.7 \\
\hline
\end{tabular}

${ }^{* *}$ significance ${ }^{\#}$ nonsignificant tendency ${ }^{\text {a }}$ diagnosed dementia vs control group ${ }^{b}$ possible dementia vs control group ${ }^{c}$ possible dementia vs diagnosed dementia.

MMSE Mini Mental State Examination, ATC Anatomical Therapeutic Chemical classification system, SSRI serotonin re-uptake

inhibitors, SNAC Swedish National Study of Aging and Care questionnaire, CSDD Cornell Scale for Depression in Dementia, MNA-SF shortform Mini-Nutritional Assessment, MNS Modified Norton Scale. 